\title{
DIABETES AND VAGINAL SURGERY ARE ASSOCIATED WITH MIXED URINARY INCONTINENCE IN PATIENTS TREATED IN A TERTIARY UNIT OF RIO DE JANEIRO PUBLIC HEALTHCARE SYSTEM
}

\author{
Carlos Augusto Faria ${ }^{1}$, Juliana Branco Dias², \\ Maria Luiza Garcia Rosa ${ }^{3}$, Sandra Costa Fonseca ${ }^{3}$
}

\begin{abstract}
Introduction: Urinary incontinence (UI) is prevalent in women, and the frequency of its clinical subtypes varies according to the population studied and the choice of diagnostic criteria. The aim of this study was to evaluate the distribution of the most common subtypes - stress urinary incontinence (SUI) and mixed urinary incontinence (MUI) - and their correlation with demographic, clinical and reproductive factors of patients seen at the university hospital of Universidade Federal do Rio de Janeiro.
\end{abstract}

Methods: This cross-sectional study was conducted in a referral service of a tertiary care center. A retrospective analysis of records of 770 women referred to the urogynecologic outpatient clinic was performed. The clinical diagnosis of UI subtype was established in accordance with international standardization. Women presenting with SUI and MUI were compared in terms of age, reproductive history, comorbidities, medications used and gynecological surgeries. The effect of independent variables was assessed through multiple regression analyses.

Results: The frequency of the clinical diagnosis of MUI and SUI was, respectively, $54.6 \%$ and $31.8 \%$. Factors associated with MUI when compared with SUI were diabetes mellitus (odds ratio, OR $=1.75 ; 95 \%$ confidence interval, $95 \% \mathrm{Cl}=1.08$; 2.85 ) and perineoplasty $(\mathrm{OR}=1.79 ; 95 \% \mathrm{Cl}=1.18 ; 2.72)$. Age showed a borderline significance $(p=0.05)$.

Conclusions: The distribution of UI subtypes was different from the distribution found in populational studies, which shows the specific aspects of women referred for specialized care. MUI was the most common subtype and was associated with previous vaginal surgery and diabetes mellitus when compared with SUI.

Keywords: Urinary incontinence; urge; urinary incontinence; stress; women's health; epidemiology

Urinary incontinence (UI) is reported in the literature as a key, independent factor that affects aging well in women. Therefore, efforts should be made to better understand this condition and minimize its effects on the general population through prevention and treatment measures ${ }^{1}$.

European epidemiological studies have shown that, based on each clinical category, $50 \%$ of all women with UI are classified as having stress urinary incontinence (SUI), followed by mixed urinary incontinence (MUI) and overactive bladder $(\mathrm{OB})^{2}$. The prevalence of these subtypes varies with age, and older women show a higher prevalence of $\mathrm{MUI}^{2-4}$.

Several factors related to the increasing prevalence of UI, such as age and parity, have already been cited in the literature at length ${ }^{5,6}$. Currently, with changes in life expectancy and lifestyle, other factors have emerged, such as chronic diseases and the medications used to treat them ${ }^{7}$.

In Brazil, there is an increasing interest in the prevalence, risk factors and distribution of female Ul8-12. Women living in urban areas in the Midwest region and in the Southeast region of the country present a prevalence of
Clin Biomed Res. 2017;37(3):163-168

1 Department of Maternal and Child Health, School of Medicine, Universidade Federal Fluminense (UFF). Niterói, RJ, Brazil.

2 Department of Gynecology, Universidade Federal do Rio de Janeiro (UFRJ). Rio de Janeiro, RJ, Brazil.

3 Department of Epidemiology and Biostatistics, School of Medicine, Universidade Federal Fluminense (UFF). Niterói, RJ, Brazil.

Corresponding author: Carlos Augusto Faria carlosfaria@vm.uff.br Faculdade de Medicina, Universidade Federal Fluminense (UFF) Rua Marques do Paraná, 303, Centro. 24033-900, Niterói, RJ, Brazil. 
UI ranging from $21.4 \%$ to $32.9 \%{ }^{9-12}$. Those with a higher number of pregnancies and births and with a higher body mass index (BMI) have a greater risk of developing $\mathrm{UI}^{12}$. In terms of its subtypes, SUI has been the most studied. Its prevalence ranges from $15.3 \%$ in postmenopausal women to $35 \%$ in climacteric women according to studies conducted, respectively, in the cities of São Luís ${ }^{13}$ and Campinas ${ }^{14}$. Socioeconomic and reproductive risk factors related to SUI were not identified in these studies.

While SUI has well-established standards for diagnosis and treatment, MUI is a major challenge, since it combines SUI and urge urinary incontinence $(\mathrm{UUI})^{3}$. This definition was standardized by international societies based on the clinical assessment of symptoms and may induce bias, as symptoms can be difficult to express in appropriate medical terms in different regions and countries around the world ${ }^{15}$.

It is not clear whether MUI has its own pathophysiology with an underlying mechanism different from the one responsible for SUI or UUI ${ }^{16}$. Women with MUI are a very heterogeneous group, and their most bothersome complaint may vary from one individual to another. This may serve to justify the discrepancy observed in prevalence rates and makes the identification of risk factors very complex. In addition, the negative impact of MUI on the quality of life, which seems to be more significant than the impact of SUI alone, may be aggravated with aging, concomitant comorbidities and the effect of drugs used in their treatment for lower urinary tract symptoms ${ }^{17,18}$.

Patients seen at university hospitals present unwieldy comorbidities, often co-existent, are frequently taking several medications and sometimes have already been treated unsuccessfully. Consequently, this population may constitute a special group with its own characteristics, different from the general population.

The aim of this study was to evaluate the distribution of the two main clinical subtypes of UI - SUI and MUI - among the female population seeking medical care at a specialized department, and also to identify their association with demographic, clinical and reproductive factors, comorbidities, use of medications and previous gynecological surgeries.

\section{METHODS}

The study was approved by the Research Ethics Committee of the university hospital Clementino Fraga Filho (HUCFF) of the Universidade Federal do Rio de Janeiro. Methods, definitions and units used in this study meet the standards jointly recommended by the International Urogynecological Association and the International Continence Society ${ }^{19}$.
The study sample consisted of 829 women referred to the HUCFF outpatient clinics. Their medical records were entered into a Microsoft Excel version 97-2003 spreadsheet (Microsoft, Redmond, WA, USA) and were retrospectively analyzed. Data on 59 women with renal lithiasis, urinary infection and genital prolapse without urinary symptoms were excluded, and 770 patients remained in the database.

Based on urinary symptoms, the patients were divided into three groups: 1) those who only complained of urine leakage due to the stress of physical activity and received a clinical diagnosis of SUI; 2) those who showed urgency associated or not with UUI, frequency, or nocturia, yet without urine leakage due to stress, and received a clinical diagnosis of $O B$; and 3) those who displayed symptoms of both SUI and $\mathrm{UUI}$ and received a clinical diagnosis of MUI ${ }^{19}$.

Patients with $\mathrm{OB}$ were excluded, and the remaining 665 women with SUI and MUI were compared in terms of age, number of deliveries, mode of delivery (none, vaginal, cesarean section, forceps, vaginal and cesarean section, vaginal and forceps, forceps and cesarean section, and all types of deliveries), and menstrual status (menacme or post-menopausal). In addition, the groups were compared based on their history of gynecological surgery (vaginal surgery for prolapse and/or UI and abdominal hysterectomy), the presence of comorbidities (diabetes and hypertension) and use of medications.

\section{STATISTICAL ANALYSIS}

In this study, a convenience sample from the HUCFF outpatient clinic database was used, and no previous sample calculation was performed.

The t-test for two independent samples was used to compare the quantitative variables of the two diagnostic groups. For the comparison of qualitative variables, a chi-square test was used with a $5 \%$ significance level.

The variables showing statistically significant differences were included in the logistic regression models. In order to identify groups of symptoms with greater association with each of the diagnoses, a forward stepwise regression was conducted. The analysis was performed using the Statistical Package for Social Sciences for Windows software, version 17.0 (SPSS, Chicago, IL, USA).

\section{RESULTS}

The mean age of the 665 patients was $56.7 \pm 11.8$ years, ranging from 21 to 88 years. The study groups comprised 420 patients with a clinical diagnosis of MUI and 245 patients with SUI. Therefore, the clinical diagnosis ratio was $1.71 \mathrm{MUI}$ cases for each SUI case. 
Table 1: Comparison of stress and mixed urinary incontinence (SUI and MUI) according to demographic, clinical and reproductive factors.

\begin{tabular}{lccc}
\hline \multicolumn{1}{c}{ Variables } & SUI $(\mathbf{n}=\mathbf{2 4 5})$ & MUI $(\mathbf{n}=\mathbf{4 2 0})$ & P-value \\
\hline Quantitative & (Mean \pm SD) & (Mean \pm SD) & 0.001 \\
Age & $54.7 \pm 11.1$ & $57.8 \pm 12.4$ & 0.04 \\
Number of deliveries & $3.03 \pm 2.07$ & $3.43 \pm 2.67$ & \\
Qualitative & $\mathrm{N}(\%)$ & $\mathrm{N}(\%)$ & 0.05 \\
Hypertension & $129(52.7)$ & $254(60.5)$ & 0.04 \\
Diabetes & $26(10.6)$ & $80(19)$ & 0.88 \\
Diuretic & $81(33.1)$ & $141(34.4)$ & 0.47 \\
Calcium blocker & $28(11.4 \%)$ & $56(13.4 \%)$ & 0.19 \\
Beta-blocker & $50(20.4 \%)$ & $104(24.8 \%)$ & 0.13 \\
ACE inhibitor & $62(25.3 \%)$ & $129(30.8 \%)$ & 0.57 \\
Benzodiazepines & $18(7.3 \%)$ & $36(8.6 \%)$ & 0.58 \\
Abdominal hysterectomy & $45(18.4 \%)$ & $70(16.7 \%)$ & $<0.0001$ \\
Vaginal surgery & $40(16.3 \%)$ & $120(28.6 \%)$ & 0.03 \\
Postmenopause* & $147(76.6 \%)$ & $296(84.3 \%)$ & \\
\hline "Infrmation frm & & \\
\hline
\end{tabular}

*Information from 543 patients. ACE = angiotensin-converting enzyme; SD = standard deviation.

The patients with SUI had a mean age lower than to those with MUI, with a statistically significant difference $(p=0.001)$. The most frequent comorbidity in both groups was hypertension $(57.6 \%)$, followed by diabetes mellitus $(16 \%)$. There was a statistically significant difference for diabetes $(p=0.04)$ and a borderline difference for hypertension $(p=0.05)$. The most commonly used medications were hypotensive drugs, especially diuretics, angiotensin-converting enzyme inhibitors and beta-blockers, but no difference was found between the two groups due to their use (Table 1).

In terms of history of gynecological surgeries, 160 women reported previous vaginal surgery for $\mathrm{UI}$ and/or genital prolapse (24\%) and 115 had had an abdominal hysterectomy (17.3\%). Vaginal surgeries were more frequent in women with MUI $(p<0.0001)$. Information about menstrual status and age of menopause was available for 543 patients $(81.7 \%)$, since 115 women had had a hysterectomy and seven did not remember when menopause occurred. The occurrence of menopause was reported more frequently in women with MUI $(p=0.03)$. Although a statistically significant difference was found between the two groups for the number of deliveries, it was not found for mode of delivery $(p=0.81$ ).

Variables showing a statistical difference between the two groups were included in a multivariate analysis, except menstrual status (menacme or postmenopausal), since it is associated with female age. In the first model, the variables of age, hypertension and number of deliveries were not significant. Age was maintained
Table 2: Final multivariate analysis model - factors associated with mixed urinary incontinence compared to stress urinary incontinence.

\begin{tabular}{lccc}
\hline \multicolumn{1}{c}{ Associated factors } & OR & $\mathbf{9 5 \%} \mathbf{C l}$ & P-value \\
\hline Age & 1.01 & $1.00-1.03$ & 0.051 \\
Diabetes & 1.75 & $1.08-2.85$ & 0.023 \\
Vaginal surgery & 1.79 & $1.18-2.72$ & 0.006 \\
\hline \multicolumn{2}{l}{ OR = odds ratio; $\mathrm{Cl}=$ confidence interval. }
\end{tabular}

in the final model due to its well-known association with the clinical UI subtypes.

The results of the final multivariate model can be found in Table 2. Women with diabetes mellitus or with a history of vaginal surgery had a greater probability, $75 \%$ and $79.7 \%$, respectively, of being diagnosed with $\mathrm{MUI}$ in comparison with SUI. Age showed a borderline significance, with each year leading to an increase of $1.4 \%$ in the probability of being diagnosed with MUI.

\section{DISCUSSION}

The number of MUI cases in the group of women included in the present study was $70 \%$ greater than the number of SUI cases. MUI was also the most common clinical diagnosis in studies conducted in older populations ${ }^{3,4}$. In addition, women seen at other Brazilian referral centers have been diagnosed with MUI more frequently ${ }^{20}$. This suggests that there are specific aspects that differentiate the study group from the general population, in which the prevalence of SUI is equal to or greater than the prevalence of $M U^{2}$. However, it is important to emphasize that the 
diagnosis of Ul subtypes was based on the reports of the patients, who are not expected to know how to describe each symptom using urologic terms ${ }^{15}$.

Women with MUI were older than those with SUI. Epidemiological studies have shown that the prevalence of MUI increases with aging ${ }^{2}$. In addition, most older women with MUI were in the postmenopausal period, which explains the difference found for the menstrual state between the groups.

According to the univariate analysis, history of hypertension was associated with MUI when compared with the SUI group. The literature shows conflicting results regarding the association between hypertension and UI, which could be due to the fact that both conditions have increasing prevalences with aging and/or to the effect of medications used for hypertension treatment ${ }^{21-23}$. An association between the medications used for symptoms of the lower urinary tract and the UI subtypes was not found.

Diabetic women can show urinary symptoms related to the clinical presentation of the disease or to the urinary tract dysfunction caused by diabetes ${ }^{23}$. Diabetes alone is one of the most relevant factors for the occurrence of UI, and patients may present, among others, symptoms of both SUI and MU122,24-25.

A significant association of diabetes with the MUI group was found. Women in this group were older and had had more deliveries. Diabetes is a chronic disease, and its prevalence increases with aging. The longer the disease has been present, the greater the risk of effects on the urinary tract, contributing to the development of UUI. In addition, diabetes can cause pelvic floor dysfunction and, when associated with a high number of childbirths, could be implicated in the genesis of leakage during effort in cases of MUI.

Parity has been widely recognized as a risk factor for pelvic floor dysfunction. Studies suggest that pregnancy and childbirth, regardless of type, are involved in the genesis and the severity of $\mathrm{UI}^{4-6,8,9,22}$. Among the 665 women included in the present study, those with MUI had had a higher number of deliveries than those who complained only of SUI. The comparison between the two groups considered the various possible types of delivery, but no difference was found. This analysis must be viewed with caution since there was data shattering, which was a confounding factor. It is worth noting that previous vaginal surgery for SUI or genital prolapse showed a significant association with the clinical diagnosis of MUI, although the technique used was unknown.
It is well-established in the literature that Kelly-Kennedy plication for SUI treatment has poor long-term results and should no longer be performed, while colporrhaphy continues to be an option for prolapse treatment ${ }^{26}$. Dissection during these procedures can cause injury to the pelvic floor and its innervation, contributing to the emergence or aggravation of urinary symptoms, which justifies an association with the clinical diagnosis of MUI. Even though the surgical indications and techniques used in the population studied were unknown, the results show that previous vaginal surgery can have deleterious effects on pelvic floor function.

According to the multivariate analysis, a history of diabetes increased the probability of MUI by $75 \%$, and a history of vaginal surgery increased it by $79.7 \%$. Age did not persist as a significant variable. With the aging process, women have a greater chance of presenting with diabetes, which in association with previous vaginal surgeries could be a preponderant factor for the emergence of $\mathrm{MUI}$ in detriment of SUI.

The main limitation of the present study is the retrospective nature of the analysis of medical records. In addition, women seen at tertiary care centers present more complex UI complaints and chronic diseases. The duration of these diseases, as well as the use of other medications, has not been evaluated yet, which can be a limiting aspect of this study. However, there is a biological plausibility underlying the notion that women with diabetes have a greater tendency to develop the mixed subtype of urinary incontinence. Furthermore, the difference in the distribution of the types of $\mathrm{UI}$ and the association between diabetes and vaginal surgeries with the clinical diagnosis of MUI is relevant, indicating that there are specific features in this group. Studies using a control group of women with chronic diseases seen at tertiary care hospitals, but without UI, should help clarify this issue and enhance knowledge of the differences found.

In conclusion, this study found that MUI was the most common Ul subtype in the female population referred for specialized consultations in a Brazilian tertiary hospital. The presence of diabetes and the history of a previous vaginal surgery increased the probability of a diagnosis of $\mathrm{MUI}$ in comparison with SUI. Further research is necessary to better understand the mechanisms of these associations.

\section{Conflicts of interest}

The authors declare no conflicts of interest. 


\section{REFERENCES}

1. Kendig H, Browning CJ, Thomas SA, Wells Y. Health, lifestyle, and gender influences on aging well: an Australian longitudinal analysis to guide health promotion. Front Public Health. 2014;2:70. PMid:25072042. http:// dx.doi.org/10.3389/fpubh.2014.00070.

2. Hunskaar S, Burgio K, Diokno A, Herzog AR, Hjälmås K, Lapitan MC. Epidemiology and natural history of urinary incontinence in women. Urology. 2003;62(4 Suppl 1):1623. PMid:14550833. http://dx.doi. org/10.1016/S0090-4295(03)00755-6.

3. Khullar V, Cardozo L, Dmochowski R. Mixed incontinence: current evidence and future perspectives. Neurourol Urodyn. 2010;29(4):61822. PMid:20432324. http://dx.doi. org/10.1002/nau.20907.

4. Barentsen JA, Visser E, Hofstetter $\mathrm{H}$, Maris AM, Dekker JH, Bock $\mathrm{GH}$. Severity, not type, is the main predictor of decreased quality of life in elderly women with urinary incontinence: a population-based study as part of a randomized controlled trial in primary care. Health Qual Life Outcomes. 2012;10(1):153. PMid:23249635. http://dx.doi. org/10.1186/1477-7525-10-153.

5. Oliveira E, Zuliani LMM, Ishicava J, Silva SV, Albuquerque SSR, Souza AMB, et al. Avaliação dos fatores relacionados à ocorrência da incontinência urinária feminina. Rev Assoc Med Bras. 2010;56(6):688-90. PMid:21271137. http://dx.doi.org/10.1590/S010442302010000600019.

6. Fritel X, Ringa V, Varnoux N, Fauconnier A, Piault S, Bréart G. Mode of delivery and severe stress incontinence. A cross-sectional study among 2,625 perimenopausal women. BJOG. 2005;112(12):164651. PMid:16305569. http:// dx.doi.org/10.1111/j.14710528.2005.00763.x.

7. Hall SA, Yang M, Gates MA, Steers WD, Tennstedt SL, McKinlay JB. Associations of commonly used medications with urinary incontinence in a community based sample. J Urol. 2012;188(1):183-9. PMid:22591967. http://dx.doi.org/10.1016/j. juro.2012.02.2575.

8. Oliveira C, Seleme M, Cansi PF, Consentino RF, Kumakura FY, Moreira $\mathrm{GA}$, et al. Urinary incontinence in pregnant women and its relation with socio-demographic variables and quality of life. Rev Assoc Med Bras. 2013;59(5):460-6. PMid:24080345. http://dx.doi.org/10.1016/j. ramb.2013.08.002.

9. Gomes GV, Silva GD. Incontinência urinária de esforço em mulheres pertencentes ao Programa de Saúde da Família de Dourados (MS). Rev Assoc Med Bras. 2010;56(6):649-54. PMid:21271129. http://dx.doi.org/10.1590/S010442302010000600011.

10. Tamanini JT, Lebrão ML, Duarte YA, Santos JL, Laurenti R. Analysis of the prevalence of and factors associated with urinary incontinence among elderly people in the Municipality of São Paulo, Brazil: SABE study (health, wellbeing and aging). Cad Saude Publica. 2009;25(8):1756-62. PMid:19649416. http://dx.doi.org/10.1590/S0102311X2009000800011.

11. Santos CRS, Santos VLCG. Prevalence of urinary incontinence in a random sample of the urban population of Pouso Alegre, Minas Gerais, Brazil. Rev Lat Am Enfermagem. 2010;18(5):90310. PMid:21120409. http:// dx.doi.org/10.1590/S010411692010000500010.

12. Amaro JL, Macharelli CA, Yamamoto H, Kawano PR, Padovani CR, Agostinho AD. Prevalence and risk factors for urinary and fecal incontinence in Brazilian women. Int Braz J Urol. 2009;35(5):592-8. PMid:19860938. http://dx.doi.org/10.1590/S167755382009000500011.

13. Brito LG, Brito LM, Chein MB, Malheiros ES, Duarte TB, Pinto AM NO. Stress urinary incontinence in climacteric women in a northeastern Brazilian municipality: a household survey. Int Urogynecol J. 2012;23(5):639-45. PMid:22411207. http://dx.doi.org/10.1007/s00192-0121697-z.

14. Guarisi T, Pinto AM NO, Osis MJ, Pedro AO, Paiva LH, Faúndes A. Incontinência urinária entre mulheres climatéricas brasileiras: inquérito domiciliar. Rev Saude Publica. 2001;35(5):428-35. PMid:11723513. http://dx.doi.org/10.1590/S003489102001000500004.
15. Radziszewski P, Dybowski $B$. Incontinence: do we speak the same language? Eur Urol. 2014;65(1):968. PMid:24055432. http://dx.doi. org/10.1016/j.eururo.2013.09.008.

16. Myers DL. Female mixed urinary incontinence: a clinical review. JAMA. 2014;311(19):2007-14. PMid:24846038. http://dx.doi. org/10.1001/jama.2014.4299.

17. Asoglu MR, Selcuk S, Cam C, Cogendez E, Karateke A. Effects of urinary incontinence subtypes on women's quality of life (including sexual life) and psychosocial state. Eur J Obstet Gynecol Reprod Biol. 2014;176:187-90. PMid:24630299. http://dx.doi.org/10.1016/j. ejogrb.2014.02.008.

18. Coyne KS, Wein A, Nicholson $\mathrm{S}$, Kvasz M, Chen Cl, Milsom I. Comorbidities and personal burden of urgency urinary incontinence: a systematic review. Int $\mathrm{J}$ Clin Pract. 2013;67(10):1015-33. PMid:24073974. http://dx.doi. org/10.1111/ijcp.12164.

19. Haylen BT, Ridder D, Freeman RM, Swift SE, Berghmans B, Lee J, et al. An International Urogynecological Association (IUGA)/International Continence Society (ICS) joint report on the terminology for female pelvic floor dysfunction. Neurourol Urodyn. 2010;29(1):4-20. PMid:19941278.

20. Rodrigues MP, Barbosa LJF, Ramos JGL, Maurer L, Catarino BM, Thomaz $\mathrm{RP}$, et al. Perfil das pacientes do ambulatório de uroginecologia de um hospital público de Porto Alegre com relação à incontinência urinária e à qualidade de vida. Clin Biomed Res. 2016;36(3):135-41. http://dx.doi. org/10.4322/2357-9730.64817.

21. Alvaro R, Araco F, Gravante G, Sorge R, Overton J, Vellone E, et al. Epidemiological aspects of urinary incontinence in a female population of an Italian region. Int Urogynecol J. 2010;21(7):873-83. PMid:20179905. http://dx.doi.org/10.1007/s00192-0101112-6.

22. Waetjen LE, Liao S, Johnson WO, Sampselle CM, Sternfield B, Harlow $\mathrm{SD}$, et al. Factors associated with prevalent and incident urinary incontinence in a cohort of midlife women: a longitudinal analysis of data: study of women's health 
across the nation. Am J Epidemiol. 2007;165(3):309-18. PMid:17132698. http://dx.doi.org/10.1093/aje/kwk018.

23. Tannenbaum C, Gray M, Hoffstetter S, Cardozo L. Comorbidities associated with bladder dysfunction. Int J Clin Pract. 2013;67(2):10513. PMid:23305472. http://dx.doi. org/10.1111/ijcp.12085.
24. Gomez CS, Kanagarajah P, Gousse $A E$. Bladder dysfunction in patients with diabetes. Curr Urol Rep. 2011;12(6):419-26. PMid:21894526. http://dx.doi.org/10.1007/s11934-0110214-0.

25. Perera J, Kirthinanda DS, Wijeratne S, Wickramarachchi TK. Descriptive cross sectional study on prevalence, perceptions, predisposing factors and health seeking behaviour of women with stress urinary incontinence. BMC Womens Health. 2014;14(1):78. PMid:24985068. http://dx.doi. org/10.1186/1472-6874-14-78.

26. Bergman A, Elia G. Three surgical procedures for genuine stress incontinence: five-year follow-up of a prospective randomized study. Am J Obstet Gynecol. 1995;173(1):6671. PMid:7631729. http://dx.doi. org/10.1016/0002-9378(95)90171-X.

Received: May 10, 2017 Accepted: July 31, 2017 